\title{
Current state of exploration and actual problems of tectonics, seismology and seismotectonics of Armenia
}

\author{
J. K. Karapetyan ${ }^{1,2}$, R. S. Sargsyan ${ }^{1}$, K. S. Kazaryan ${ }^{1}$, B. V. Dzeranov ${ }^{2,3}$, B. A. Dzeboev ${ }^{2,3}$, and \\ R. K. Karapetyan ${ }^{1}$
}

Received 2 March 2020; accepted 27 March 2020; published 10 April 2020.

This article analyzes the current state of exploration of the tectonic structure and seismotectonics of Armenia as well as the results of seismological studies. Current problems in this area are identified. The analysis of seismotectonic maps created by various researchers is carried out and the main contradictions in their construction are highlighted. The authors have estimated the accuracy of the earthquake catalogs of Armenia for the periods 1962-1990 and 1991-2018. The main problems affecting reliable statistical analysis of earthquake catalogs are identified. The main causes of these uncertainties as well as possible solutions are described in detail. The article provides a review of seismotectonic studies in Armenia. The results of previous research are mainly aimed at establishing focal zones of strong earthquakes and assessing the seismotectonic potential of the main seismogenic structures. The article presents the method used in those explorations. Considering existing problems in the fields of tectonics, seismology and geodynamics, it is very relevant to conduct new research, including the development of GNSS observations, and application of updated seismological data. KEYWORDS: Tectonics; seismology; seismotectonics; seismogenic structures; seismotectonic potential; Armenia.

Citation: Karapetyan, J. K., R. S. Sargsyan, K. S. Kazaryan, B. V. Dzeranov, B. A. Dzeboev, and R. K. Karapetyan (2020), Current state of exploration and actual problems of tectonics, seismology and seismotectonics of Armenia, Russ. J. Earth. Sci., 20, ES2005, doi:10.2205/2020ES000709.

\section{Introduction}

The territory of the Republic of Armenia belongs to the tectonically active and earthquakeprone zone of the Caucasus. This is expressed in modern slow creep movements of the earth's surface and fast seismogenic movements along faults and in their intersection nodes. Throughout his-

\footnotetext{
${ }^{1}$ Institute of Geophysics and Engineering Seismology after A. Nazarov, Gyumri, Armenia

${ }^{2}$ Geophysical Center RAS, Moscow, Russia

${ }^{3}$ Geophysical Institute, Vladikavkaz Scientific Center RAS, Vladikavkaz, Russia
}

Copyright 2020 by the Geophysical Center RAS. http://rjes.wdcb.ru/doi/2020ES000709-res.html tory, several catastrophic earthquakes occurred in Armenia, including historical ones - Garni, 1679; Cilicia, 1268, etc. On 7 December 1988, near the city of Spitak, an earthquake occurred ( $M=7.0$, $I_{0}=9-10$ points), which killed about 25 thousand people.

Tectonics is probably the most multifaceted and hard access for geophysicists and geologists of all the existing fields of Earth Sciences. Most likely, this is the reason for the enormous scientific interest that has existed in this science for decades.

The relevance of explorations in the field of tectonics and seismicity is especially growing when it comes to geodynamically active regions of the Earth. One of such territories is Armenia, occupying the southern part of the Lesser Cauca- 


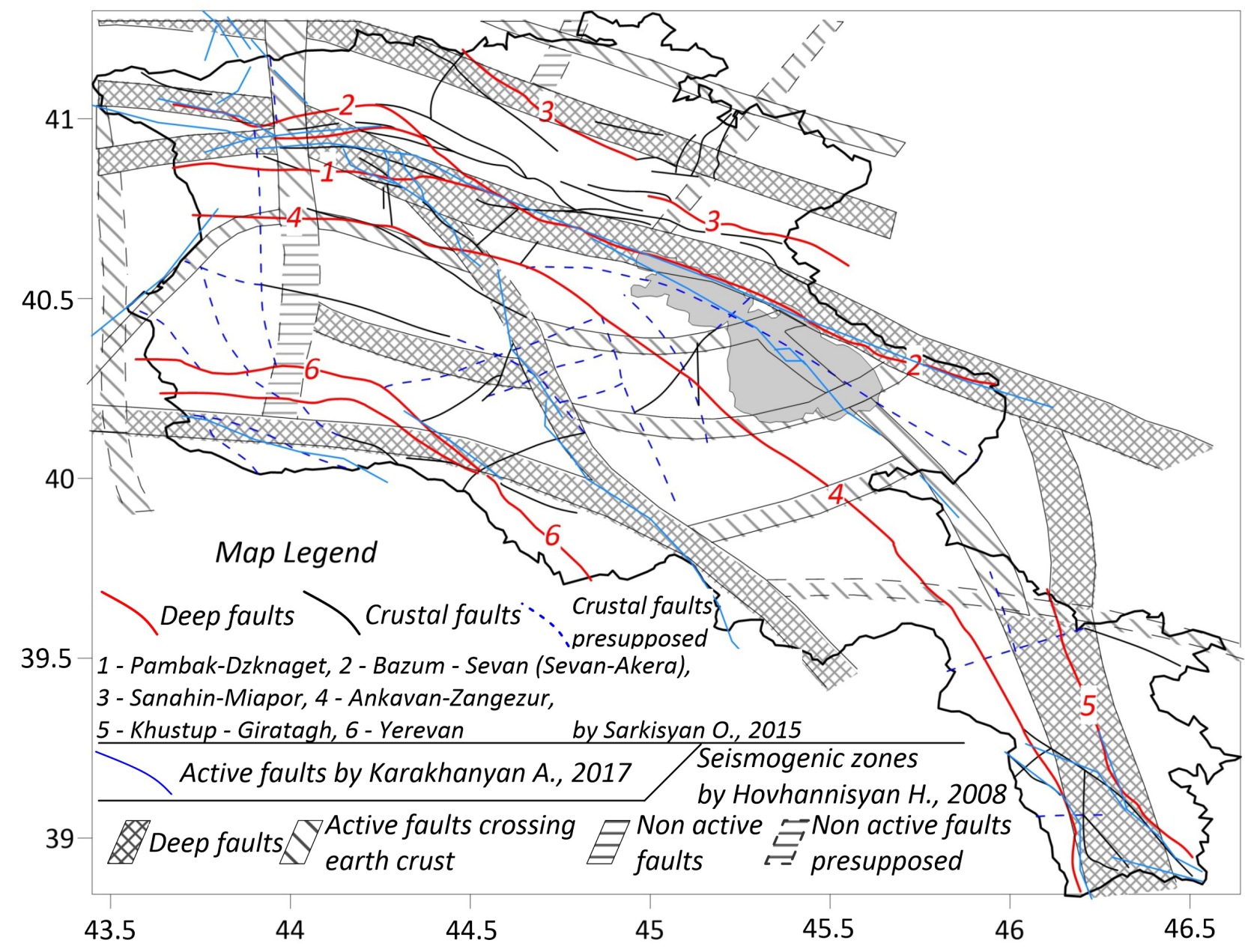

Figure 1. Fault scheme in the territory of Armenia according to the data of geological and geophysical explorations Hovhannisyan et al., 2008. Karakhanyan et al., 2017. Sarkisyan and Shakhbekyan, 2015.

sus, located on the north-eastern peripheral zone of the Armenian Highlands. The territory of Armenia is located in the collision zone between the Arabian (from the south) and Eurasian (from the north) lithospheric plates. This territory for millions of years experiences the full power of this phenomenon in the form of dynamic crustal movements and frequent strong earthquakes. This is the reason for the great scientific interest in tectonics and seismotectonics in this region.

\section{Tectonics of Armenia}

A substantial number of studies conducted by K. Paffengoltz, L. Vardanyants, E. Milanovsky, A. Gabrielyan, A. Aslanyan, O. Sargsyan, G. Si- monyan and others is devoted to this problem. As a result, tectonic schemes of Armenia with the identification of the main fault formations were developed, tectonic units of the territory were identified, geotectonic zoning was conducted, etc. The geotectonic zoning scheme of Armenia, compiled by Gabrielyan 1974, was widely used at that time and a large number of seismotectonic problems were solved on its basis. The research results were subsequently systematized in [Gabrielyan et al., 1981].

Based on this map in 2015, the first large-scale (1 : 200,000) tectonic map of the territory of Armenia was compiled [Sarkisyan and Shakhbekyan, 2015. This map reflects the main tectonic structures (Figure 1.

In 1993, the scheme of active faults of the Armenian Highlands was published [Karakhanyan, 1993, which was then corrected in 2004 


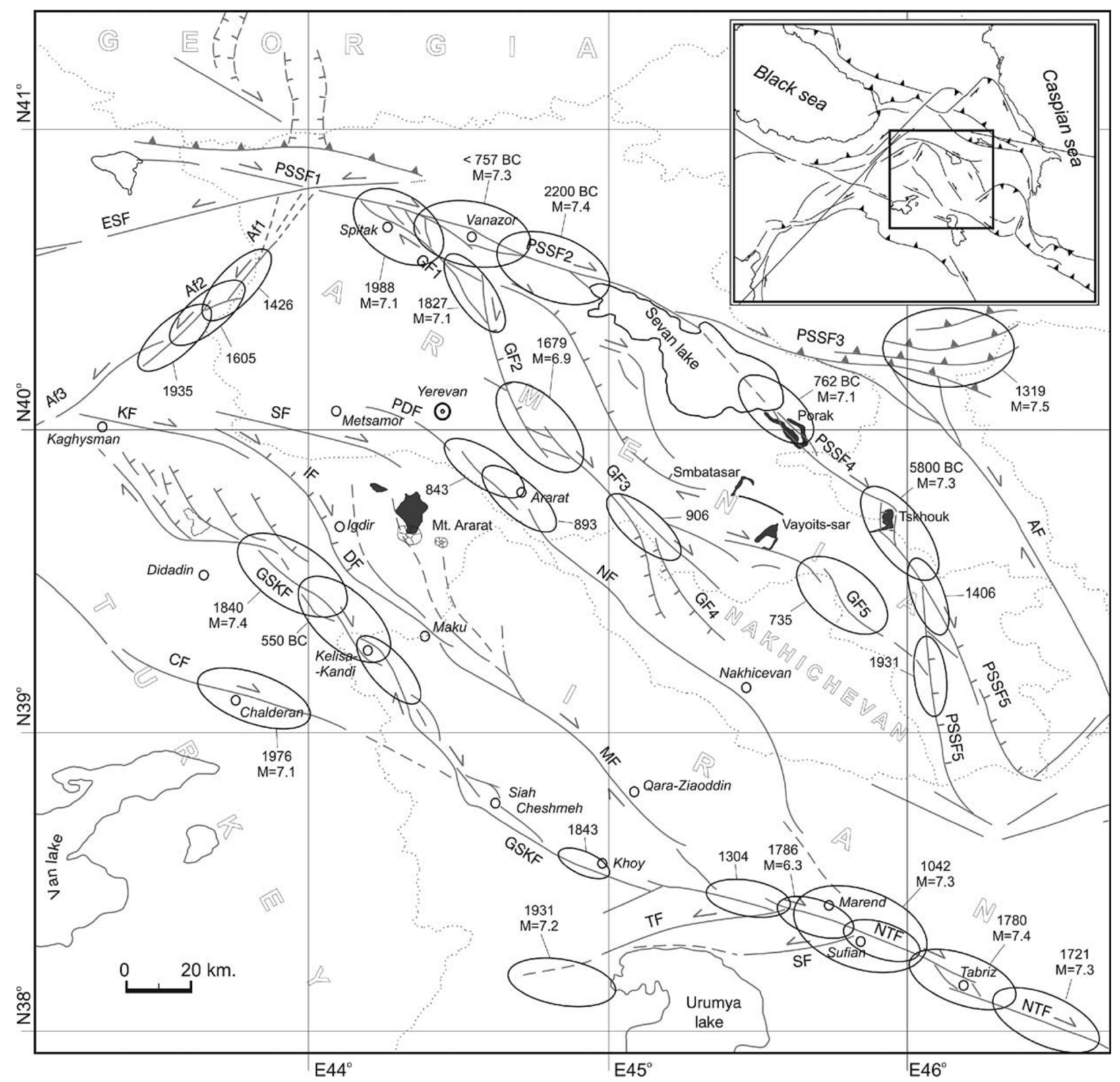

Figure 2. Schematic map of active faults in the territory of Armenia, according to A.Karakhanyan [Karakhanyan, 1993, Karakhanyan et al., 2004].

[Karakhanyan et al., 2004 (Figure 2). In this scheme, the author refers to active faults as faults that display tectonic activity in the last 100 thousand years.

As a result, they identified faults: PambakSevan-Syunik (PSSF), Garni (GF), Akhuryan (Af), Zheltorechensk-Sarykamysh (ESF), ParakarDvinsk (PDF), Sardarapat (SF), Nakhichevan (NF), Akerinsk (AF) faults. A number of faults were also identified on the territory of the Javakheti and Geghama volcanic massifs of predominantly strike fault nature.

Comparison of these schemes shows the presence of a number of contradictions. First of all, this concerns changes in schemes over time. So, in 2017, a refined scheme of active tectonics was published [Karakhanyan et al., 2017 (Figure 3). The absence of a number of faults that were previously present in the works of 1993, 2004 is striking. First of all, these are Akerinsk and Nakhichevan faults. How- 


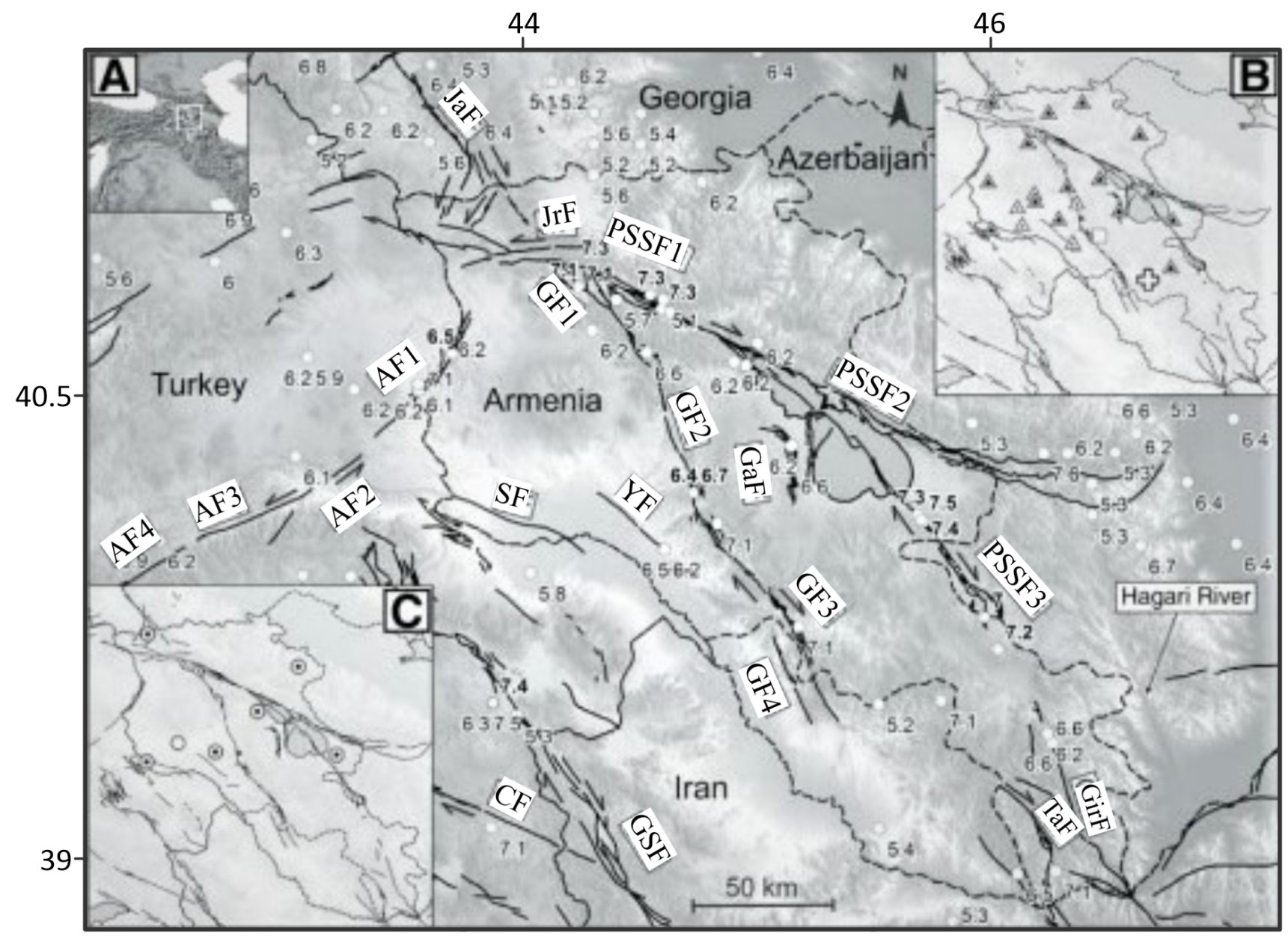

Figure 3. Schematic map of active faults in the territory of Armenia, according to A.Karakhanyan [Karakhanyan et al., 2017].

ever, there are no reasons for this. The Nakhchivan Fault (NF), here appears as the fourth segment of the Garni Fault (GF4). Other faults have undergone significant changes in terms of their extension. The Parakar-Dvinsk Fault (PDF) was described by the author as the northwestern branch of the Nakhichevan Fault, and in the new scheme, the Parakar-Dvinsk Fault was renamed the Yerevan Fault (YF) and appeared as a short segment that dramatically changed its submeridian (NW$\mathrm{SE}$ ) direction to sub-latitudinal one, extending east to the junction with the Garni Fault.

The Zheltorechensk-Sarykamysh Fault has undergone significant changes. It used to cross the first segment of the Pambak-Sevan-Syunik Fault (PSSF1) in the form of a left-side shift at an oblique angle and extended to Turkey. In the last scheme, only the Zheltorechensk Fault (JrF) is indicated, which has a northwestern extension to Lake Cildir.
It can be seen that the nameless strike fault of the Javakheti Highlands, which is here referred to as the Javakheti Fault (JaF), has undergone changes. Instead of a slip fault, here we already see a right-side slip fault. This fault extends along the watershed of the ridge in the submeridian direction from the northwest to the southeast. Another nameless fault with left-right shear kinematics stretches to the west of this fault from the northeast to the south-west. The Javakheti Fault from the south is joined with the Zheltorechensk Fault, and the Abul-Samsar Fault with the North Amasi (ANF) Fault, which together with the South Amasi Fault (ASF) represent the northwest branches of the Pambak-Sevan-Syunik Fault.

Considering the picture of faults of the same region by other authors, for example, the scheme of Gamkrelidze et al. [1998, we can observe a different picture. Gamkrelidze used a whole set of data, 
both geological-morphological and geophysical, to draw up a diagram of active faults in the territory of Georgia. He notes that the Abul-Samsar and Javakheti faults are strike faults. In addition, this entire region is surrounded by the Loki-Agdam fault of sub-latitudinal strike, which has an average seismic activity. However, as we see in the 2017 map, this fault is absent and is not identified as active. In addition, as early as in 1969, S. P. Balian in his monograph [Balian, 1969 for the Javakheti Highlands mentioned that there is no fault along the axial zone of the Javakheti ridge, and the ridge is divided into segments by sub-latitudinal faults, which is also not outlined in the 2017 map.

There are many contradictions concerning the Pambak-Sevan-Syunik Fault in the area of Lake Sevan. Here in [Karakhanyan et al., 2017) (Figure 3), as newly discovered, it is noted that in the light of new data, the Pambak-Sevan-Syunik Fault, to which the Giratakh (GirF) and Tashtun (TaF) faults were genetically attributed, in fact do not have any structural genetic connection between themselves and are completely different structural elements.

In this regard, it should be noted that, several decades earlier, the authors identified the AnkavanZangezur deep fault, crossing the lake Sevan from the west and having NW-SE strike (see Figure 1). It extended eastward along the southern side of the Shirak basin in the sub-latitudinal direction, then crossing the lintel of the Tsakhkunyats and Pambak ranges diverged into two branches. The first of them sharply turned south-southeast, crossed the Geghama ridge at an oblique angle, then crossed the entire Zangezur ridge from north to south through the Vardenis ridge and the Syunik volcanic plateau, including the Tashtun Fault. The second branch of the Ankavan-Zangezur Fault continued through the valley of the Marmarik River and crossed Sevan Lake from northwest to southeast, then skirting the Vardenis ridge from the east, joined through the Syunik volcanic plateau in a southern direction with the Giratakh Fault. Authors who studied the tectonics of Armenia have never noted any structural-genetic connection between the Pambak-Sevan-Syunik, Tashtun and Giratakh faults. At the same time, in [Karakhanyan et al., 2017, the third segment of the PambakSevan-Syunik Fault (PSSF3) breaks off in the Syunik volcanic highlands. The question arises - what is its continuation. It should be pointed out that the works of Gabrielyan, Sargsyan and Simonyan, instead of the Pambak-Sevan-Syunik Fault, mentioned the Sevan-Akerin deep fault, which is also the boundary between the two geotectonic zones of Armenia - the Sevan-Shirak geosyncline and the Somkheto-Kafan geoanticline.

Concerning the data obtained on the basis of GPS observations, the author emphasizes [Karakhanyan et al., 2013 that they relate to the time interval 1998-2009. Such a modest period can in no way demonstrate the general kinematics of movements along faults, taking into account the cyclical effect of geodynamic movements indicated in other known works.

Next, we will try to analyze the achievements and uncertainties of seismological studies in Armenia at the present time.

\section{Results of Seismological Studies}

Due to the high seismic activity of the territory of Armenia, one of the most relevant areas of geodynamic research is seismology. To study seismicity and obtain reliable results, first of all, you need to have a unified and representative catalog of seismic events. The reliability analysis of the source materials is one of the main parts of seismological research. The accuracy of the catalog includes the data representativeness of earthquakes that occurred in the study area, as well as the estimation of errors in determining the parameters of earthquakes [Karapetyan, 2018, Karapetyan et al.,2020.

Inhomogeneous data in the catalogs of earthquakes arise due to the quantitative and spatial changes in seismic networks over time. The fact is that with the development of the seismological network, the representativeness of earthquakes can change [Burmin et al., 2014]. It should be noted that the catalogs published in the collections "Earthquakes in the USSR" since 1967 were limited by the energy class level $K \geq 9$, and were rounded off by the integer value of the class for a number of years. After the 1988 Spitak earthquake, the number of seismic stations increased in the Republic of Armenia and earthquakes were recorded already from $K \geq 8$. When studying seismic activity, the basis is the catalog of earthquakes in 
Table 1. Summary of Hypocenter Parameters of the Earthquake 08.11.2005 According to Various Seismic Services (Date and Time of Earthquake: 08.11.2005, 06:27:11.7)

\begin{tabular}{llccccc}
\hline $\begin{array}{l}\text { Seismic } \\
\text { service }\end{array}$ & Full name & Lat. & $\begin{array}{c}\text { Lon. } \\
\text { NSP }\end{array}$ & $\begin{array}{c}\text { Type } \\
\text { of mag- } \begin{array}{c}\text { Mag- } \\
\text { nitude } \\
\text { tude }\end{array}\end{array}$ & $\begin{array}{c}\text { Depth, } \\
\text { km }\end{array}$ \\
\hline NSSP & National Seismic Protection Service, Yerevan, Armenia & 40.983 & 44.933 & ML & 3.8 & 10.0 \\
TIF & Georgian Seismic Monitoring Center, Tbilisi, Georgia & 40.869 & 48.144 & - & - & 17.4 \\
CSEM & European Mediterranean Seismological Centre, France & 40.793 & 47.639 & mb & 4.1 & 2.0 \\
IDC & International Data Center, Vienna, Austria & 40.838 & 47.476 & $\mathrm{mb}$ & 4.0 & 24.9 \\
MOS & Geophysical Survey RAS, Obninsk, Kaluga Region, & 41.163 & 47.473 & $\mathrm{mb}$ & 4.1 & 43.0 \\
& Russia & & & & & \\
NEIC & National Earthquake Information Center, USGS & 40.622 & 47.528 & $\mathrm{mb}$ & 4.1 & 84.1 \\
NNC & Kazakhstan National Data Center, Almaty & 41.364 & 48.309 & - & - & 14.5 \\
ISC & International Seismological Centre, UK & 41.067 & 47.617 & $\mathrm{mb}$ & 3.9 & 33.0 \\
\hline
\end{tabular}

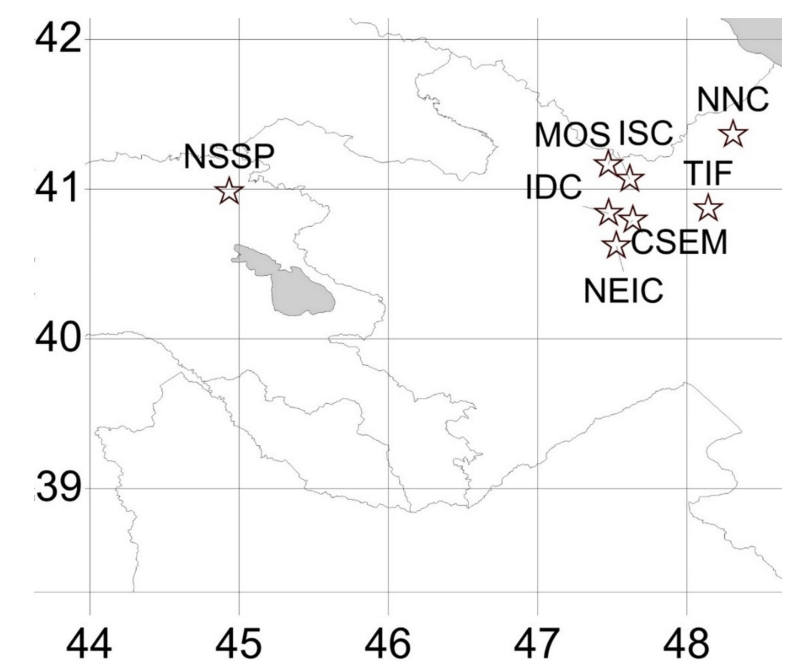

Figure 4. Coordinates of the epicenter of the 08.11.2005 earthquake according to world seismological services.

the territory: the catalog of earthquakes in Armenia includes a catalog of instrumental data and a catalog of historical earthquakes. In the process of creating earthquake catalogs, data at different time intervals often have different levels of reliability due to different collection procedures, data analysis methods, available information, etc. For earthquakes recorded during instrumental observations, compiling seismic catalogs has different levels of integrity over time and space due to changes in network density in the studied time interval. It is easy to verify that the determination of the earthquake hypocenters by different services and methods, according to different hodographs and obser- vation systems, gives mixed results. Confirmation of this is Table 1 that is compiled according to the International Seismological Center (ISC).

As it can be seen from Figure 4 when calculating the epicenter of this earthquake by different seismological services, there are also large differences. For example, the data presented by the NSSP seismic service, the coordinates of the earthquake epicenter are about $300 \mathrm{~km}$ away from other results.

To study the spatiotemporal distribution of earthquake hypocenters and analyze the reliability of data from earthquake catalogs in the territory of Armenia, the time interval was divided into two stages - 1962-1990 and 1991-2018.

The data from bulletins of seismic stations of the Caucasus and the data from the funds of the GSRAS were used as the source data (Seismological bulletin of the Caucasus, 1973-1990. Tbilisi, "Metznireba", in Russian; Seismological Bulletin of Armenia. Foundations of the National Seismic Protection Service of the Republic of Armenia, 19872015, in Russian; International Seismological Center, 1962-2018, http://www.isc.ac.uk/).

Historical data on strong earthquakes were taken from the database of the catalog of the Caucasus earthquakes from $M \geq 4.0$ from ancient times to the instrumental period (Godzikovskaya, A. A., 2000, Database "Earthquake catalogue for the Caucasus with $M \geq 4.0(K \geq 11.0)$ from ancient times to the year 2000", WDCB, Moscow, in Russian http://zeus.wdcb.ru/wdcb/sep/caucasus/catrudat). Figure 5 shows the spatial distribution of earthquake epicenters in the territory of Armenia and 


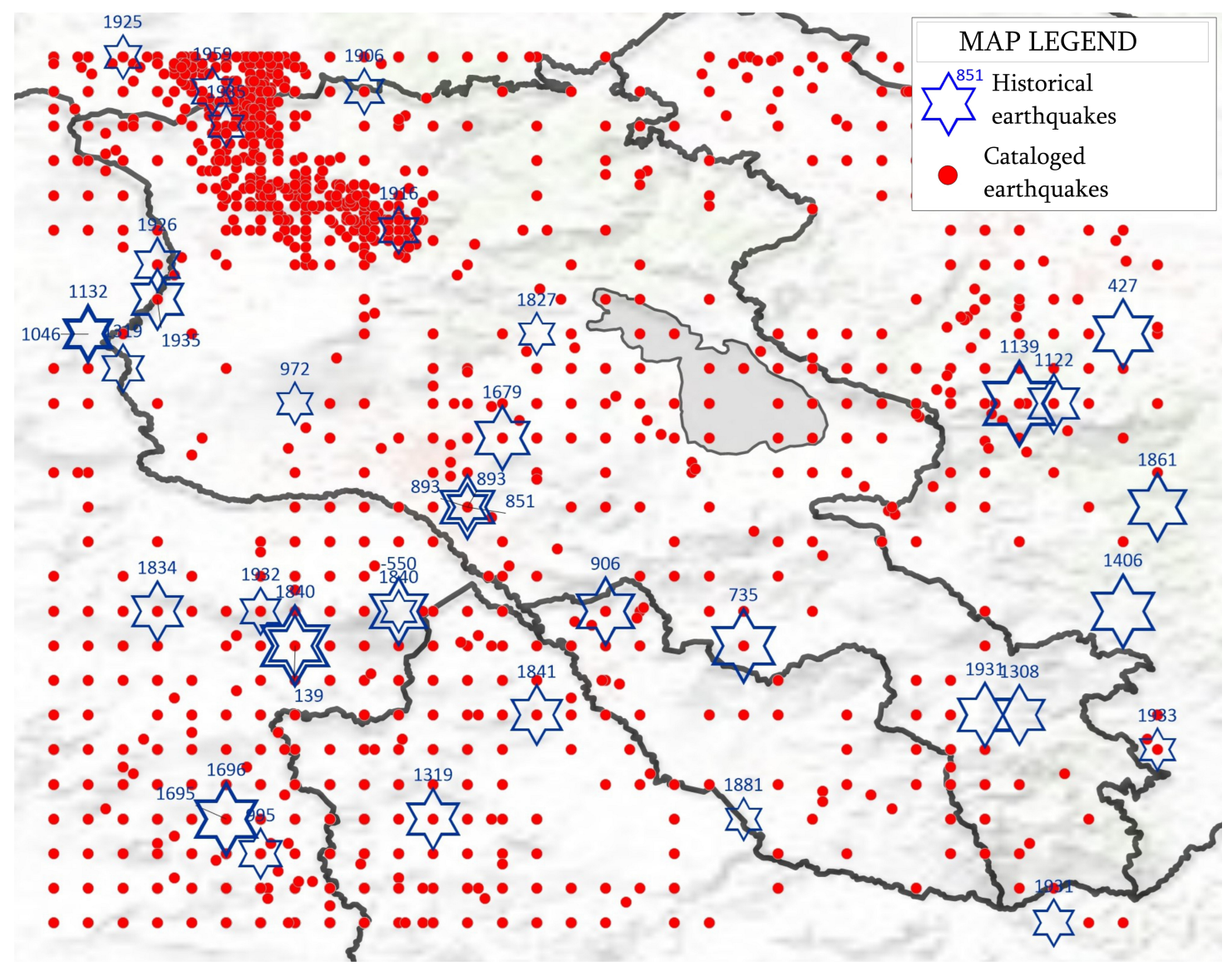

Figure 5. Spatial distribution of earthquake epicenters in the territory of Armenia and adjacent areas for the period 1962-1990 and historical strong earthquakes according to catalog data.

adjacent areas for the period 1962-1990 and historical strong earthquakes.

As can be seen from Figure 5 earthquake epicenters over the specified time period are evenly distributed over almost the entire explored territory, with the exception of the northwestern part of Armenia and the Javakheti Highlands. The use of such data in studying the confinement of earthquake focuses to certain geological structures and revealing the spatial patterns for the distribution of earthquake epicenters will not yield fundamental results. Based on this distribution of epicenters, one can assume the absence of block structures in the territory of Armenia, which contradicts the results of numerous studies and the structure of the upper part of the earth's crust in this region. The existence of accuracy problems in determining the coordinates of earthquake hypocenters of the study area are described in [Burmin et al., 2016, 2018.

The distribution of the epicenters of historical earthquakes also raises some questions. In particular, as can be seen from the map from 851 to 893 in the central part of Armenia the Dvina earthquakes with magnitudes from 5.2 to 6.4 occurred. The coordinates of the earthquake epicenters were located at the same point that is not possible both from the tectonic position and when studying statistical data, and there are several such examples. Consequently, the localization of the epicenters of historical earthquakes was carried out with large approximations.

Figure 6 shows the distribution of hypocenters in the latitudinal direction for the period 1962-1990.

It can be seen that the depths of the earthquake sources in the study area were determined approximately, since they are expressed mainly by discrete values of $5,10,20,25$, and $50 \mathrm{~km}$. This circumstance is explained by the fact that the processing of seismological material was carried out using the Levitskaya-Lebedeva hodograph built for 


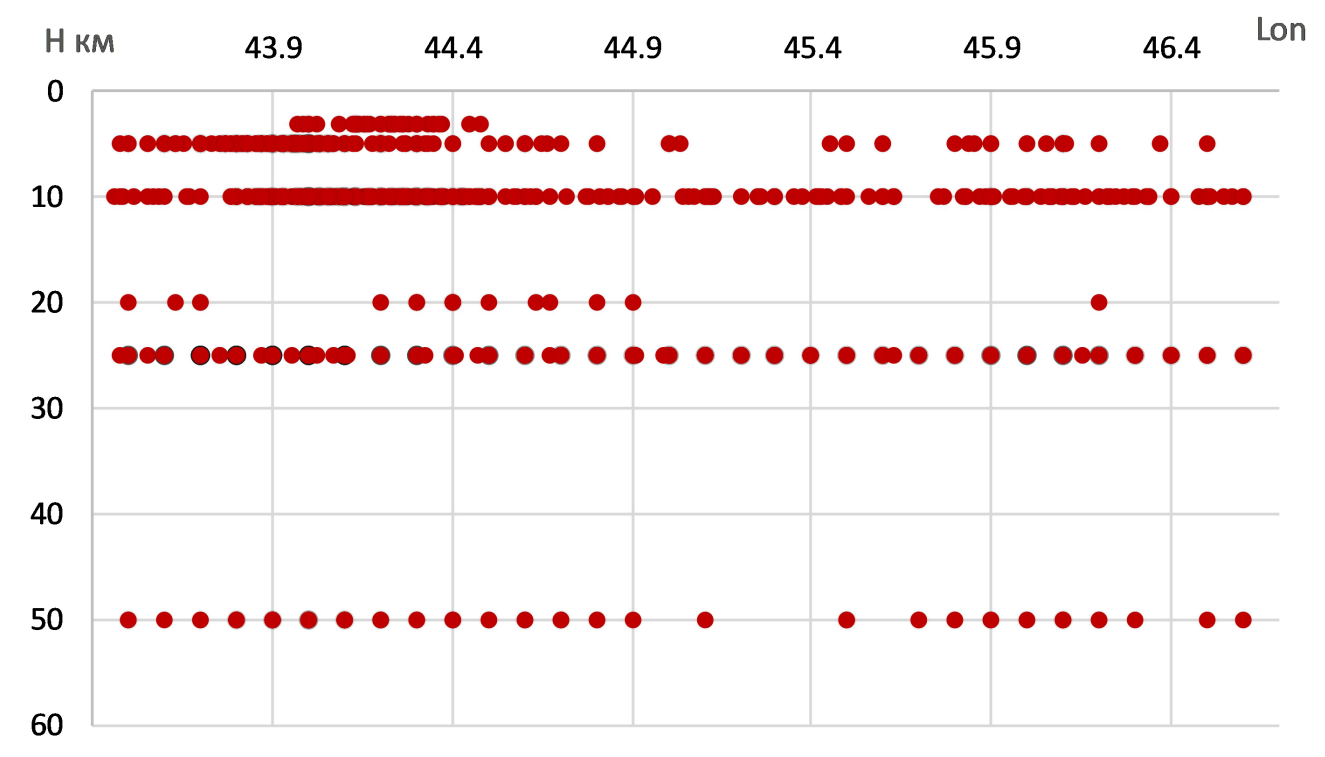

Figure 6. Distribution of earthquake hypocenters in the territory of Armenia and surrounding areas for the period 1962-1990.

earthquakes in the Transcaucasia and the isochron pattern method of Ya. V. Riznichenko, constructed according to the hodographs of A. Saakyan for focal depths $H=5,10,15,20,25 \mathrm{~km}$, as well as [Levitskaya and Lebedeva, 1953. Therefore, these approximate values are given in the catalogs of earthquakes.

Figure 7 shows the spatial distribution of the earthquake epicenters of the territory of Armenia and surrounding areas for the period 1991-2018.

Having studied the catalog data for the specified period, it should be noted that the artificial lattice type of epicenters continues until the 2000s.

Since 2006, other problems have arisen that affect the reliability of statistical analysis. As pointed out in [Artemov and Mikhailova, 2014], industrial explosions were identified in the catalogs of earthquakes in the territory of Armenia. In this regard, the amount of information in the catalogs of earthquakes sharply increased and amounted to $N=$ 1306, 1901 and 1667 seismic events, respectively, in 2006-2008, while in 2004, 2005 were recorded respectively 560 and 546 earthquakes. All events are presented by the catalog authors as earthquakes. Such a sharp increase in the number of events deserves special consideration and it is important for the correct assessment of the spatio-temporal dynamics of seismic processes in Armenia.
Figure 8 shows the distribution of hypocenters for the period 1991-2018.

As can be seen from the figure, the depths of the earthquake sources do not exceed $60 \mathrm{~km}$ and again there are approximate values of $5,10,25 \mathrm{~km}$.

\section{Seismotectonics}

It is known that the territory of Armenia covers the North-Eastern peripheral part of the Armenian Highlands and is located in the Alp-Himalayan seismically active belt. Here, for historical and modern periods of observations, earthquakes with $M>6.0$ are known, which belong to the category of destructive ones, and earthquakes with magnitudes $M>4.5$ are numerous. This circumstance determines the urgency of the tasks regarding the establishment of possible seismic sources (hereinafter referred to as PSS) of strong earthquakes and the assessment of the seismotectonic potential of the main seismogenic zones of Armenia.

Despite the high seismic activity in Armenia, there is a limited number of works devoted to the identification of strong earthquakes PSS. Superiority among them belongs to the work of Gabrielyan and Piruzyan 1972, where the authors first put 


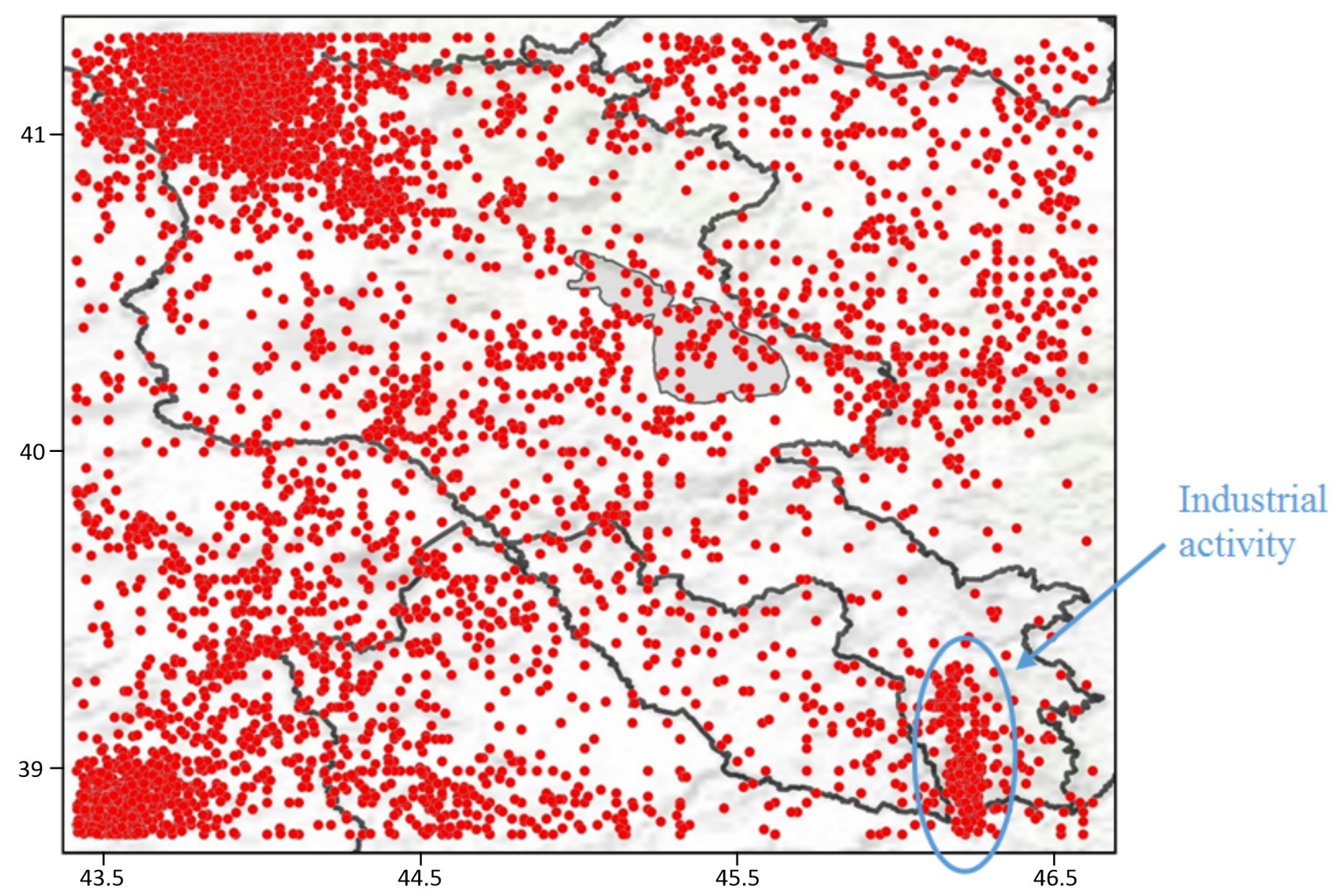

Figure 7. Spatial distribution of earthquake epicenters in the territory of Armenia and adjacent areas for the period 1991-2018.

forward the most important idea of the spatial confinement of strong and weak earthquakes to certain structural-tectonic zones. The authors of the article wrote, "Areas characterized by differentiated and contrasting types of recent movements are more seismically active. The greater the change in sign and speed of the latest and modern movements along strike and in time, i.e. the larger their gradient, the higher is the seismic activity". In the same work, the authors extend this conclusion to the main five geotectonic zones in the territory of Armenia.

In Gabrielyan et al. 1981, a review of strong historical earthquakes from a structural-tectonic position is made. However, it is known that each geotectonic zone of Armenia has its own internal complex block structure, and, therefore, the interpretation of seismic activity at this level is largely generalized, which makes it impossible to examine in more detail the patterns of seismic activity within the geotectonic zones themselves.
Approximately the same conclusion can be drawn from the thesis [Boynagryan, 2005, devoted to the identification of seismically active structures of Armenia according to morphostructural data. Here, the author notes that the epicenters of earthquakes are mainly confined to those neotectonic structures that at the latest stage underwent tectonic movements with different signs (upthrowns and downthrowns). However, the specified detail of studies is also not provided in this work.

A number of works on the establishment of PSS and the seismotectonic potential assessment were carried out in IGES NAS RA. Among them, one can note the work [Gasparyan et al., 2019, Geodakyan et al., 2016. Hovhannisyan et al., 2008. In these works, the concept of a seismically active stratum and its block structure was first put forward. According to this study, the seismically active stratum includes the top most part of the earth's crust in the territory of Armenia, with an average thickness of $20 \mathrm{~km}$, in which the main 


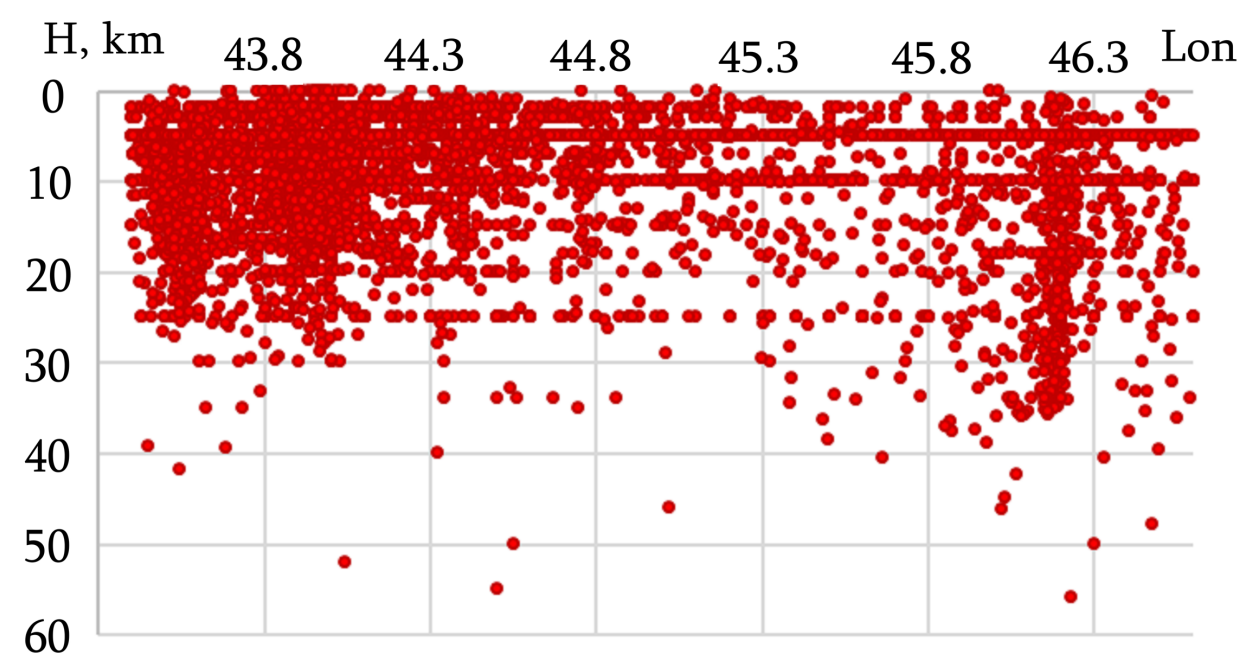

Figure 8. Distribution of earthquakes hypocenters in the territory of Armenia and surrounding areas for the period 1991-2018.

part of the recorded earthquakes sources are concentrated. Further, the authors conducted gravity modeling in order to identify the block structure of the seismically active stratum. For this purpose, in relation to a conventionally accepted surface $(20 \mathrm{~km}$ deep), the authors distinguish a number of blocks, some of which are downthrown, and the other part is upthrown (Figure 9).

As was noted in the seismology section, the choice of the thickness of the seismically active stratum is due to discrete depths values of the earthquake sources, since catalogs and bulletins were used as sources of the initial data. With such approximate and discrete values, it is impossible to unambiguously state the main characteristics of the seismically active stratum. The reliability of such a study and the results obtained is generally called into question when considering the spatial distribution of the earthquake sources in the territory of Armenia (Figure 5).

Assessment of the seismotectonic potential of faults was carried out mainly on the basis of previously recorded seismic events. Of course, the authors pay some attention to the geological and tectonic characteristics of seismogenic zones, in particular, to the extent of their strike, to the sizes of interacting blocks, to the epicentral distance of strong earthquakes, etc. However, nevertheless, the main indicator for the seismotectonic potential assessment is seismological data, in particular, the magnitude values of recorded strong earthquakes.
As a result of this approach, fault segments where no strong seismic events were recorded during the instrumental period artificially obtained low values of the seismotectonic potential, while those in which strong earthquakes were observed, on the contrary are high.

In the works [Gasparyan et al., 2019, the socalled "source-volume" concept is used [Bath and Duda, 1964. Based on this concept, the geometric characteristics of the blocks, most importantly their volume, serve as indicators for assessing the seismotectonic potential. The tectonic basis for this study was the same structural-dynamic diagram of the seismically active stratum, which has been discussed above. Its structural elements were not changed, the depth of the blocks remained the same, only the volume of blocks was calculated, after which, using empirical dependences, a transition was made from the volume of the block to possible values of $M_{\max }$.

In recent years, in the world practice of seismological studies aimed at studying the PSS and assessing the seismotectonic potential of the territory, the study of the stress-strain state of the earth's crust is the most relevant. Today, there is a variety of methods and computer programs for solving this problem, through local reconstruction of tectonic stresses [Delvaux and Speerner, 2003 . Imaev et al., 2015. Imaeva et al., 2017, Lander, 2004. Morozov and Manevich, 2016: Morozov et al., 2018a, 2018b, Rebetskiy et al., 2016. Part of 


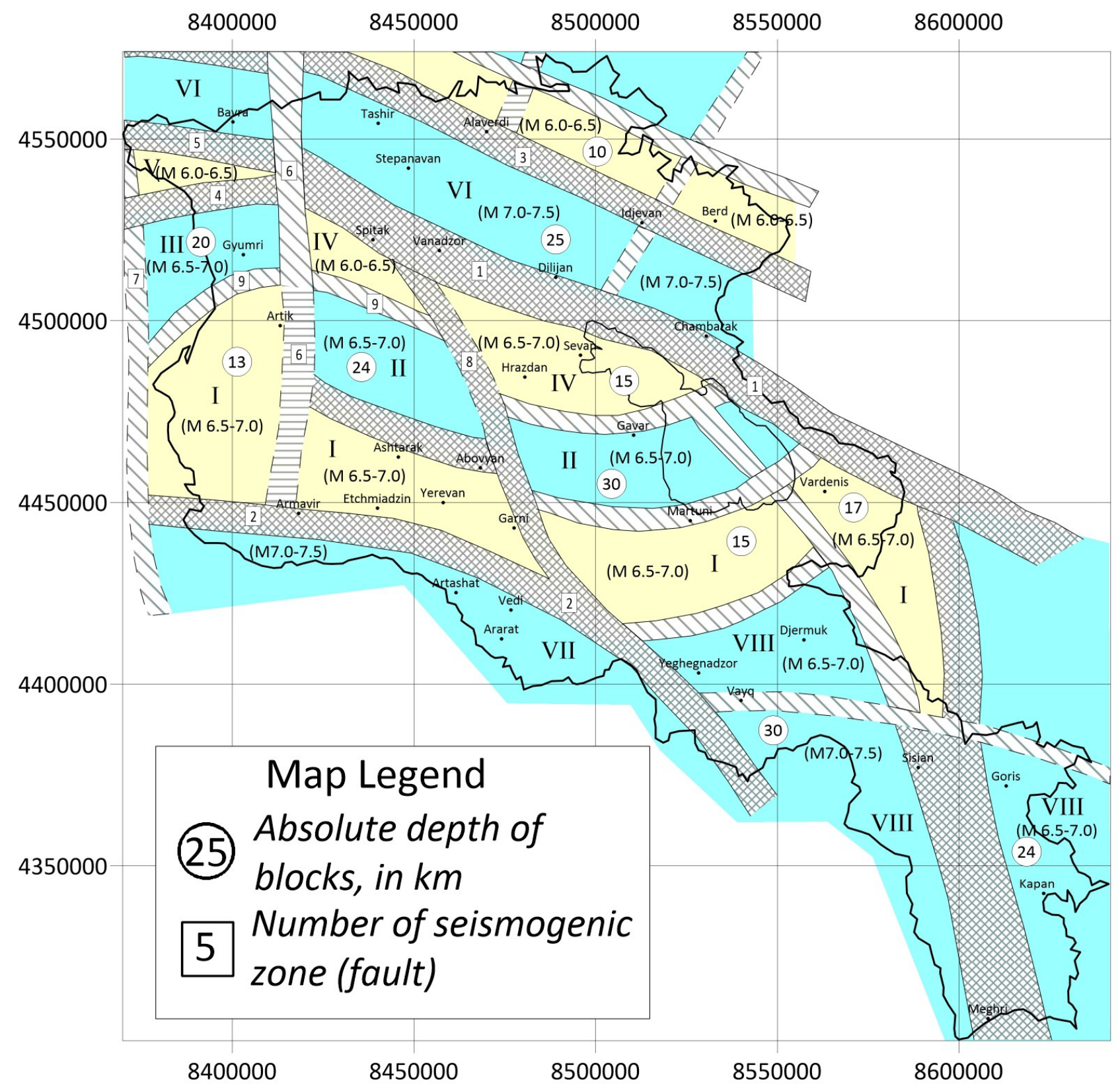

Figure 9. The structural-dynamic model of the seismically active stratum for the territory of Armenia and the possible seismotectonic potential according to [Hovhannisyan et al., 2008. Faults: 1 - Pambak-Sevan, 2 - Yerevan, 3 - Ninotsminda-Metsavan, 4 Vardaghbyur-Amasia, 5 - Arpi-Vardaghbyur, 6 - Aragats-Javakheti, 7 - Transcaucasian suture, 8 - Garni-Spitak, 9 - Ani-Bayandur-Alagez.

the research is based on studying the mechanisms of strong earthquakes, identifying on this basis the main axes of compression and extension of the terrain, and on further assessing the seismotectonic potential of the terrain by introducing GPS observations [Guojie Meng et al., 2019, Riaz et al., 2019. Xiaoning Su et al., 2019]. Another part of the work is based on a comprehensive study of geological and geophysical data and on the application of appropriate computer programs for PSS identification [Dzeboev et al., 2019a, 2019b, Grigoryan et al., 2019. Karapetyan and Karapetyan, 2019, Soloviev et al., 2013.

Summarizing the above, as well as taking into ac- 
count all the gaps existing in the study of the structure, tectonics and geodynamics of the territory of Armenia, and the practical lack of modern GNSS observations (since after the article [Karakhanyan et al., 2013 there are no new data or works according to GNSS observations in the territory of Armenia), in our opinion, the solution to the problem of detecting PSS for strong earthquakes and the assessment of seismotectonic potential are the most relevant areas of seismotectonic research in Armenia.

\section{Conclusions}

Summing up the above, it should be noted that there are many contradictions in the results of tectonic studies in Armenia. In this regard, the first priority should be the compilation of a reasonable and accurate map of the tectonic structure of the territory, with the identification of block structures and active faults. When drawing up this scheme, all existing geological and geophysical materials and tectonic schemes should be taken into account, as well as modern geographic information technologies and Earth remote sensing materials should be applied.

In the field of seismological research, it is necessary to emphasize the importance of applying the most accurate seismological data to obtain reliable results in connection with the study of the confinement of earthquake focuses to certain tectonic structures and the study of the deep structure.

Based on the solution of the aforementioned problems in the fields of tectonics and seismology, which are essentially of primary importance, new prospects will open up for studying the seismotectonic problems of Armenia using a modern methodological approach and reliable data.

Thus, the most urgent tasks are the following - the study of spatial seismicity patterns, a comprehensive assessment of the tectonic activity of blocks, the identification of focal zones of strong earthquakes, the study of the stress-strain state of the earth's crust, and assessment of the seismotectonic potential.

All these areas for the solution of which active research is currently underway are the most relevant and strategic for IGES NAS RA.
Acknowledgments. This work was supported by the RAMES Science Committee, in the frames of the research project No.18SH-1E012.

\section{References}

Artemova, E. V., $\quad$ R. S. Mikhailova (2014), Possible explosions in the catalog of earthquakes of the Republic of Armenia for 2006-2008, Modern methods of processing and interpretation of seismological data. Proceedings of the ninth international seismological school p. 49-53, GS RAS, Obninsk. (in Russian)

Balian, S. P. (1969), Structural geomorphology of the Armenian Highlands and fringing regions, $390 \mathrm{pp}$. YSU Publishing House, Yerevan. (in Russian)

Bath, M., S. J. Duda (1964), Earthquake volume, fault plan area, seismic energy, strain, deformation and related quantities, Annals of Geophysics, 17, No. $3, \quad 353-368$.

Boynagryan, A. V. (2005), Identification of seismically active structures of the territory of Armenia according to morphostructural data, PhD thesis (Geology), p. 21, YSU, Yerevan. (in Russian)

Burmin, V. Yu., A. M. Avetisyan, N. A. Sergeeva, et al. (2014), Some Seismicity Regularities of the Caucasus, Seismic Instruments, 50, 192-195, Crossref

Burmin, V. Yu., I. B. Shemeleva, L. D. Fleyfel, et al. (2016), Results of seismological data processing for the territory of Armenia, Voprosy Inzhenernoi Seismologii (Problems of Engineering Seismology), 43, No. 1, 29-39. (in Russian)

Burmin, V. Yu., I. B. Shemeleva, L. D. Fleyfel, et al. (2018), Spatial distribution of crustal earthquakes in the Caucasus, Voprosy Inzhenernoi Seismologii (Problems of Engineering Seismology), 45, No. 1, 39-48, (in Russian) Crossref

Delvaux, D., B. Speerner (2003), New aspects of tectonic stress inversion with reference to the Tensor program, New Insights into Structural Interpretation and Modeling, Nieuwland D. A. (ed.), Special Publications p. 75-100, Geological Society, London.

Dzeboev, B. A., A. A. Soloviev, B. V. Dzeranov, et al. (2019a), Strong earthquake-prone areas recognition based on the algorithm with a single pure training class. II. Caucasus, $M \geq 6.0$. Variable EPA method, Russian Journal of Earth Sciences, 19, ES6005, Crossref

Dzeboev, B. A., A. D. Gvishiani, I. O. Belov, et al. (2019b), Strong Earthquake-Prone Areas Recognition Based on an Algorithm with a Single Pure Training Class: I. Altai-Sayan-Baikal Region, $M \geq 6.0$, Izvestiya, Physics of the Solid Earth, 55, No. 4, 563-575, Crossref

Gabrielyan, A. A. (1974), Geotectonic zoning of the territory of the Armenian SSR, Bulletin of the 
Academy of Sciences of the Armenian SSR, Earth Sciences, No. 4, 3-21. (in Russian)

Gabrielyan, A. A., O. A. Sarkisyan, G. P. Simonyan (1981), Seismotectonics of the Armenian SSR, YSU Publishing House, Yerevan. (in Russian)

Gabrielyan, A. A., S. A. Piruzyan (1972), Seismotectonic scheme of Armenia and adjacent parts of Anticaucasus, Bulletin of the Academy of Sciences of the Armenian SSR. Earth sciences, No. 4, 24-33. (in Russian)

Gamkrelidze, I., T. Giorgobiani, S. Kuloshvili, et al. (1998), Active Deep Faults Map and Catalogue for the Territory of Georgia, Bulletin of the Georgian Academy of Sciences, 157, No. 1, 80-85.

Gasparyan, G. S., et al. (2019), About the level of seismotectonic potential of the Anatolian-CaucasianIranian region of the Mediterranean-Pacific belt, Problems of tectonics of continents and oceans. Proceedings of the LI Tectonic meeting, Vol. 1 p. 135-140, GEOS, Moscow. (in Russian)

Geodakyan, E. G., J. K. Karapetyan, V.B. Zaalishvili, et al. (2016), Spectral analysis of the seismic impact in near zone of strong earthquake and effect details, Geology and Geophysics of the South of Russia, 6, No. 4, 164-171, (in Russian) Crossref

Grigoryan, V. G., J. K. Karapetyan, K. S. Kazaryan, et al. (2019), Seismic hazard on the territory of Armenia: seismic zoning normative maps. Preliminary version of the new general seismic zoning map, Geology and Geophysics of the South of Russia, Vladikavkaz, 9, No. 1, 71-83. (in Russian)

Guojie, Meng, Su Xiaoning, et al.

(2019), Present-day strain accumulation in the Liupan Shan area, northeastern margin of the Tibetan Plateau by GPS observations, Terrestrial Atmospheric and Oceanic Sciences, Terr. Atmos. Ocean. Sci., 30, No. 1, 51-62, Crossref

Hovhannisyan, S. M., et al. (2008), Identification of zones of occurrence of earthquake sources on the basis of seismological identification and parameterization of the main elements of the structural-dynamic model of the Earth's crust of Armenia, Izvestiya NAS RA. Earth Sciences, No. 1, 39-43. (in Russian)

Imaev, V. S., L. P. Imaeva, O. P. Smekalin, et al. (2015), A seismotectonic map of Eastern Siberia, Geodynamics 83 Tectonophysics, 6, No. 3, 275-287, (in Russian) Crossref

Imaeva, L. P., G. S. Gusev, et al. (2017), Geodynamic activity of modern structures and tectonic stress fields in Northeast Asia, Geodynamics $\&$ Tectonophysics, 8, No. 4, 737-768, (in Russian) Crossref

Karakhanian, A. S., V. G. Trifonov, H. Philip, et al. (2004), Active faulting and natural hazards in Armenia, eastern Turkey and northwestern Iran, Tectonophysics, 380, No. 3-4, 189-219, Crossref

Karakhanyan, A., A. Arakelyan, A. Avagyan, et al. (2017), Aspects of the seismotectonics of Armenia: New data and reanalysis, Tectonic Evolution, Collision, and Seismicity of Southwest Asia. In
Honor of Manuel Berberian's Forty-Five Years of Research Contributions p. 445-475, Geological Society of America, Boulder, USA. Crossref

Karakhanyan, A., P. Vernant, E. Doerflinger, et al. (2013), GPS constraints on continental deformation in the Armenian region and Lesser Caucasus, Tectonophysics, 592, 39-45, Crossref

Karakhanyan, A. S. (1993), Active faults of the Armenian Upland, Proceedings of Scientific Meeting on the Seismic Protection, 12-13 July, Venice p. 8893, Palazzo Balbi, Venice.

Karapetyan, J. K. (2018), Study of seismicity and seismological investigations on the territory of Armenia, International Conference for the Decade Memory of the Wenchuan Earthquake with The 4th International Conference on Continental Earthquakes (The 4th ICCE) and The 12th General Assembly of the Asian Seismological, May 12-14, 2018, Chengdu, Sichuan, China, the 4th ICCE-0000000904 p. 908916, ICCE, China.

Karapetyan, J., R. Karapetyan (2019), Geophysical and engineering-seismological research in Armenia main directions, achievements and prospects for development, Geophysical Research Abstracts, 21, 328-332.

Karapetyan, J., K. Ghazaryan, R. Sargsyan, et al. (2020), Efficiency assessment of seismological information, monitoring system and seismicity study for the Republic of Armenia, EGU General Assembly 2020, EGU2020-11385, Abstracts EGU, Vienna, Austria. Crossref

Lander, A. V. (2004), The FA2002 Program System to Determine the Focal Mechanisms of Earthquakes in Kamchatka, the Commander Islands and the Northern Kuriles (Report), 250 pp. KEMSD GS RAS, Petropavlovsk-Kamchatsky.

Levitskaya, A. Ya., T. M. Lebedeva (1953), Hodograph of seismic waves of the Caucasus, Quarterly Seismic Bulletin, XXI, No. 1-4, 51-59. (Tbilisi, in Russian)

Morozov, V. N., $\quad$ A. I. Manevich (2016), Modeling stress-strain state of the epicenter zone of the earthquake 26.01.2001, $M=6.9$ (India), Geophysical Research, 17, No. 4, 23-36. (in Russian)

Morozov, V. N., V. I. Kaftan, V. N. Tatarinov, et al. (2018a), Numerical Modeling of the StressStrain State and Results of GPS Monitoring of the Epicentral Area of the August 24, 2014 Earthquake (Napa, California, USA), Geotectonics, 52, 578 588, Crossref

Morozov, V. N., V. N. Tatarinov, I. Y. Kolesnikov, et al. (2018b), Modeling the Stress-Strain State in the Epicentral Zone of a Strong Earthquake in Iran (December 26, 2003, $M w=6.6$ ), Izvestiya. Physics of the Solid Earth, 54, No. 4, 602-611, Crossref

Rebetsky, Y. L., N. A. Sycheva, V. N. Sychev, et al. (2016), The stress state of the northern Tien Shan crust based on the KNET seismic network data, Russian Geology and Geophysics, 57, No. 3, 387408, Crossref 
Riaz, M. S., B. Shan, N. Shahid, et al. (2019), Over 100 years of faults interaction, stress accumulation, and creeping implications, on Chaman Fault System, Pakistan, International Journal of Earth Sciences, 108, 1351-1359, Crossref

Sarkisyan, O. A., T. A. Shakhbekyan (2015), The first large-scale $(1: 200,000)$ tectonic map of Armenia, YSU Scientific Papers. Geology and Geography, No. 3, 10-19. (in Russian)

Soloviev, A. A., O. V. Novikova, A. I. Gorshkov, et al. (2013), Recognition of potential sources of strong earthquakes in the Caucasus region using GIS technologies, Doklady Earth Sciences, 450, 658-660, (in Russian)Crossref

Xiaoning, Su, Yao Lianbi, et al. (2019), Crustal Deformation on the Northeastern Margin of the Tibetan Plateau from Continuous GPS Observations, Remote Sensing, 11, No. 1, 34.

Corresponding author:

J. K. Karapetyan, IGES NAS RA, 5 V. Sargsyan St., 3115 Gyumri, Republic of Armenia.(jon_iges@mail.ru) 